\title{
AN INTEGRATED PRODUCTION, DISTRIBUTION, AND INVENTORY PLANNING SYSTEM
}

\author{
Fred Glover \\ University of Colorado, Boulder, Colorado 80309 \\ Gene Jones \\ Agrico Chemical Company, Tulsa, Oklahoma 74103 \\ David Karney \\ The Williams Companies, Tulsa, Oklahoma 74103 \\ Darwin Klingman \\ University of Texas at Austin, Austin, Texas 78712 \\ John Mote \\ Analysis, Research, and Computation, Inc., Austin, Texas 78765
}

Abstract. The critical importance of integrating production, distribution, and inventory (PDI) operations has long been recognized by top management of many companies. Now, using the latest advances in Management Science modeling and solution technology, an integrated computer-based PDI system has saved approximately \$18 million dollars during its first three years of implementation for a major national firm, Agrico Chemical Company. According to the Vice-President of Agrico Supply and Distribution, an additional \$25 million savings is anticipated over the next two years.

Brought about by close cooperation between company officials and an outside staff of Management Science consultants, the PDI system has been used extensively to evaluate the benefit/cost impact of alternative capital investments in both short-term and long-term planning decisions. The development of the system underscores the value of recent Management Science innovations that have made it possible to analyze interacting influences too numerous and complex to be analyzed adequately only a few years ago.

Advanced network methodology incorporated into the PDI system required only one one-hundredth of the computer time and cost of methodologies previously used. The power and flexibility of the new Management Science tools have also brought about increased communication and understanding of key company operations. This increased communication and understanding stems from the inherent "pictorial" nature of network-based models, which facilitates interpretation of these models and policy recommendations based upon their solution.

INVENTORY/PRODUCTION; NETWORKS/GRAPHS 


\section{Overview}

Agrico Chemical Company, with annual sales exceeding half a billion dollars, is one of the nation's largest chemical fertilizer companies. A subsidiary of The Williams Companies, Agrico mines, manufactures, and markets eight principal chemical products domestically and internationally. The company's success story, based on aggressive and forward-looking management, is typical of others in which a relatively small firm has been transformed into a leader in its field in less than a decade.

In the mid-1970's Agrico encountered unexpected difficulties. The seasonal demand characteristic of the chemical fertilizer industry was creating a chain of intricate and far reaching effects that could not be responded to adequately. As a result, the company's profit margins were being seriously eroded by steeply escalating distribution costs. It became apparent that a multitude of interdependent factors made it impossible to find a remedy through customary methods, such as studying cost figures and charts. The web of interacting influences which spanned the company's principal activities - production, distribution, and inventory - required an integrated computer-based planning system to uncover the appropriate decisions.

In 1976, David Wilson, Vice-President of Agrico Supply and Distribution, in coordination with Herb Beattie, Vice-President of The Williams Companies Information Services, created a project team to develop such a planning system. The principal objective of this team, headed by the authors, was to develop a computer-based production, distribution, and inventory (PDI) planning system which integrated the three major segments of Agrico's business decisions:

(1) the Supply Segment, consisting of production, purchases, and product exchanges with other chemical corporations (coproducers);

(2) the Storage and Customer Distribution Segment, involving sizing and locating bulk distribution centers; and

(3) the Demand Segment, involving customer demand throughout the eastern two-thirds of the United States, and locations where the product must be supplied to coproducers due to product exchange agreements.

The project team designed and implemented a PDI system utilizing recent advances in network modeling and solution technology [1], [2], [5-10], [12], [14 16]. The system was given the capability to provide planners with insight into the system-wide ramifications of their decisions. Its integrated framework allows the system to consider the relevant environmental impacts of all decisions simultaneously, thereby equipping it to provide analyses for long- and short-range planning and operational decisions.

\section{Long-range planning summary}

In long-range planning, the system is used primarily for decisions associated with the sizing and configuration of the distribution system. This helps to answer such questions as:

- Where should distribution centers be located and what should be their size?

- How much long-term inventory investment should be made? 
- How much transportation equipment is needed?

- What supply/purchase/exchange opportunities should be exploited?

In the short time that the integrated network PDI planning system has been in use at Agrico, it has already proven to be an extremely valuable decision aid for long-range planning and its effect in cutting the steeply rising distribution costs has been dramatic. Further, the system has uncovered several entirely unanticipated areas of cost savings, primarily through the evaluation of capital investment decisions.

One of Agrico's long-range studies, using this system, showed that by locating a distribution center on the upper Ohio River, $\$ 100,000$ could be saved on transportation costs. Another study revealed that it was worth $\$ 175,000$ to obtain the early completion of a new distribution center. The PDI planning system was also used to evaluate the long-range impact of changing the distribution pattern of a particular nitrogen chemical solution plant. Prior to the analysis using the PDI system, Agrico management had planned to build an additional 100,000 square foot storage facility to accommodate the forecasted growth in demand over a five-year period. The PDI planning system revealed that the additional storage facility was not cost effective. By not expanding the storage capacity Agrico realized a capital savings of $\$ 800,000$. In addition, the distribution plan suggested by the PDI system reduced the annual transportation costs for the plant by $\$ 12,000$.

Other long-range planning studies, using the PDI system, have been carried out by Agrico management, but the financial impact of the resulting decisions is more difficult to quantify. One such decision involved the closing of three small distribution centers in the midwest. The resulting capital was reinvested in rolling transportation equipment. In light of the current freight car shortage and energy cost increases, it is virtually impossible to accurately gauge the long-range affect of this decision.

The total quantifiable impact of Agrico's long-range planning studies using the PDI system is a cost savings in excess of $\$ 1$ million. However, the most substantial results have come from the usage of the PDI system for short-range planning and operational decisions.

\section{Short-range planning summary}

For short-range operational decisions, Agrico uses the integrated network-based PDI system to aid in answering questions dealing with the allocation of a defined supply of product through a specific distribution center configuration. For such decisions, the system is used to avoid unnecessary production, distribution, and inventory costs by providing the capability to evaluate alternatives on a systemwide basis. To illustrate, the model is used to decide what, where, and how much product should be produced as well as when, where, and how much product should be shipped.

Since 1976, Agrico has used the PDI planning system for operational decisions to supply its products to customers at the right time and at the least possible cost consistent with good customer service. During its first year of implementation, the PDI planning system enabled management to reduce Agrico's total distribution costs by $\$ 3.7$ million. But this is not the bottom line. 
During the first year, Agrico was unable to adopt completely the decision alternatives suggested by the PDI planning system. This partial implementation was anticipated, and is natural, since the task of rescheduling production and distribution activities is formidable.

The overall impact of the planning system is best illustrated by Figure 1. This figure shows the growth in the total cost of distribution over the past few years as well as the anticipated growth through 1980. In the figure, the projected distribution costs are those that Agrico would have expected to incur if the PDI planning system had not been developed. The projected distribution costs are based on a conservative $7 \%$ annual inflation rate applied to the known point-to-point freight rates prior to the development of the PDI system. These inflated freight rates are multiplied by the anticipated distribution tonnage to obtain the projected costs. The actual incurred distribution costs through 1978 are also shown in Figure 1. These are projected forward for 1979 and 1980 by applying the same $7 \%$ annual inflation rate of the 1978 point-to-point freight rates obtained by the PDI system. A total distribution cost savings of nearly $\$ 17$ million was made from 1976 to 1978 . It is projected that by 1980 the PDI planning system will be providing Agrico with an annual distribution cost savings in excess of $\$ 13$ million. Clearly the impact of this planning system is becoming more pronounced as the cost of energy increases.

FIGURE 1. Distribution Cost Trends.

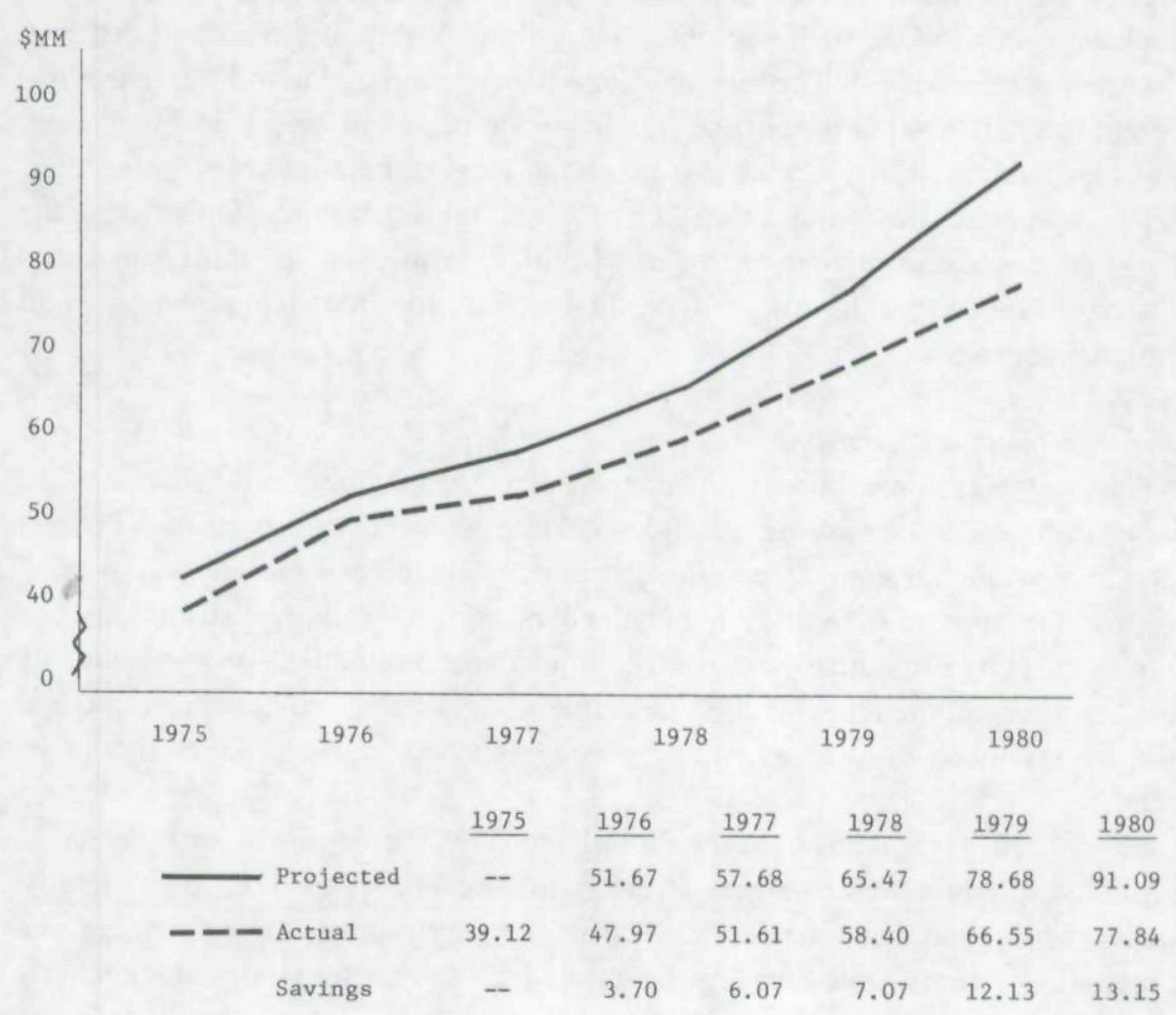


Agrico's commitment to use the PDI planning system necessitated the development of an on-line automated freight rate system. Although initially designed simply to provide input data to the PDI system, the automated freight rate system has radically altered the way Agrico rates its orders from customers. The use of the freight rate system has reduced the average billing time by approximately one day. In 1978 alone, the corresponding reduction of accounts receivable produced a working capital interest savings of $\$ 50,000$.

The system has also enabled Agrico to reduce the number of stockouts suffered by its clients by more effectively prepositioning its products in the marketplace. As a result, Agrico was able to sell nearly 50,000 more tons of product during 1978 than anticipated. This increased sales volume resulted in an additional $\$ 850,000$ of working capital.

Another outcome of the usage of the PDI system for short-range planning is improved coordination and information flow between key departments. Although it is hard to quantify the impact of this improved departmental communication, in the long run this is potentially as important as the more quantifiable cost reductions.

The fundamental features of Agrico's integrated network computer-based PDI planning system and additional benefits from using this system are detailed in the following sections.

\section{Agrico study}

\section{Background of company operations}

Agrico's eight principal chemical products are produced continuously throughout the year. However, the demand for these agricultural products is highly seasonal with approximately one-third of the annual demand occurring within a four-week span. (See Figure 2.) This graph is fairly typical of all the principal chemical products.

FIGURE 2. 1976 Ammonia Fertilizer Sales.

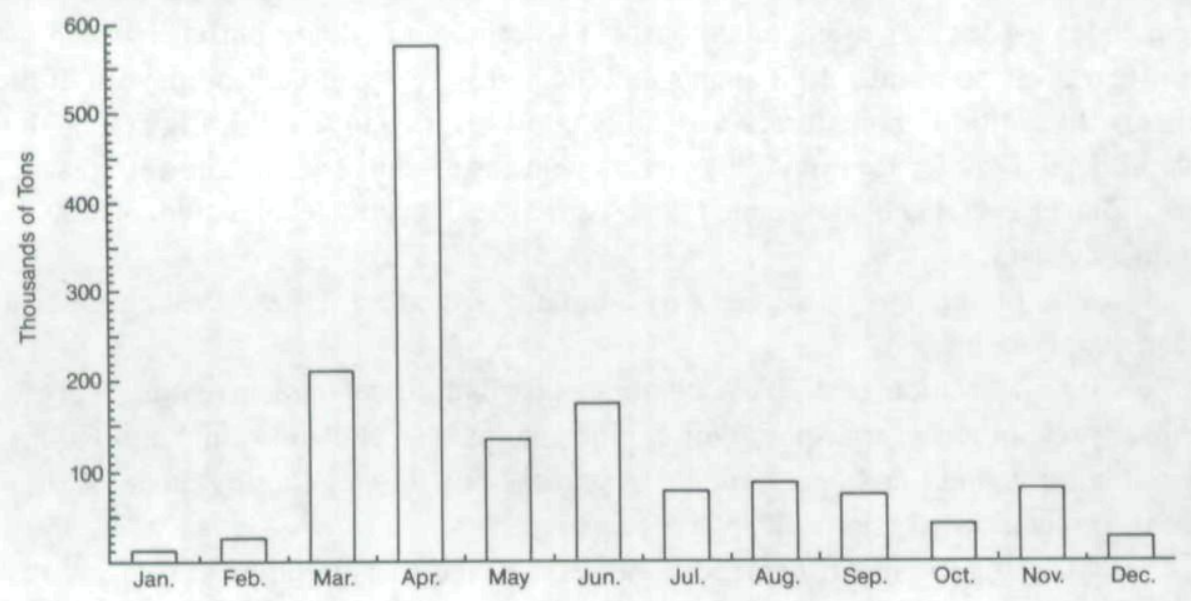


Managerial decisions relating to the distribution and inventory functions require evaluation of the following questions:

- Where should products be shipped?

- Which demand should be met?

- Which company-owned distribution centers should be used?

- Where should new distribution centers be leased and what should be their size?

- Where and how much product exchange should be made?

- How many railroad cars should be leased and purchased?

- What level of customer service provides the most cost-effective results?

- Which plants or distribution centers should service which clients?

As the size and complexity of the organization increased, it became apparent that answers to these important questions required more powerful analytical tools than previously employed. This realization was abruptly accentuated by the crisis of steeply escalating distribution costs in the mid-1970's. This led management to seek an effectively designed computer-based PDI planning system. The virtues of this decision are becoming more important due to the current energy and rail car shortages.

\section{Model development}

The interdisciplinary team, created by management to develop the PDI system, was composed of high-level company personnel and an outside staff of Management Scientists and computer specialists. It undertook as its initial effort to thoroughly analyze Agrico's existing facilities and on-going operations. Agrico has 4 production plants, 78 distribution centers, and approximately 2000 clients. The bulk distribution of product from plants to distribution centers is primarily by pipeline, barge, and rail. Shipments from distribution centers to clients also include truck and client-arranged pickup. The total bulk storage capacity of the 78 distribution centers is about 1.6 million tons, or approximately $40 \%$ of sales of the major products marketed.

A number of the distribution centers are owned and operated by Agrico and the remainder are leased on an annual basis. The centers provide a buffer between the constant production rate at the plants and the highly seasonal demand pattern of the clients. In addition, their storage capability allows Agrico to strategically preposition its products in order to provide its clients with faster deliveries at a lower cost.

The project team ascertained that Agrico had available or could obtain the following data:

- The production rates, capacity limitations, and variable operating costs at each supply point.

- Transportation costs from plants to distribution centers, inventory storage, capacity by product, transportation equipment loading and unloading limitations, variable throughput and operating costs, and the cost of stocking by mode of shipment for each distribution center in the system.

- Mode of shipment, demand to be served, and transportation costs from distribution centers for each client. 


\section{Overall model strategy}

Based on the information obtained in the initial evaluation effort, a 12-month planning horizon was selected, since Agrico's distribution center leases are on an annual basis and uncertainties in sales forecasts diminish the value of a longer planning horizon. In addition, the project team decided to partition the planning horizon into monthly time periods in order to capture the highly seasonal demand pattern.

The critical task at this stage was to identify a model that exhibited a useful degree of realism, in view of the decision objectives, yet which was efficiently solvable. The early history of Management Science applications contains numerous examples of elaborate decision-making systems which were either designed to solve the wrong problems, or designed to solve the right problems, but which utilized a model structure that could never be solved with existing solution technology. In addition, the interpretations of these models and their outcomes were often completely opaque to anyone other than the highly technical "experts" who designed them.

To avoid these pitfalls, the project team devoted special consideration to the intricate task of designing a mathematical model which could effectively incorporate all the details of Agrico's PDI problems and, at the same time, satisfy the other two important criteria of solvability and understandability. Investigation showed that a network-based model was the most useful and effective for this task because:

(1) Network models are highly solvable. Advances in network modeling and solution technology [1] - [18] have occurred over the past several years whereby problems that previously cost $\$ 1000$ to solve can now be solved for less than $\$ 10$ [8], [9]. Further, it is now possible to solve network problems vastly larger than could be solved a few years ago [1].

(2) Network models facilitate communication between specialists and nonspecialists, due to their pictorial (diagrammatic) nature [8], [9].

(3) The visual aspects of network models also contribute to increased insights into the problem structure and enable meaningful interpretation of problem solutions.

With the decision to use a network-based model, the steps of the model development could be undertaken in a manner which allowed all members of the project team to actively participate, regardless of their Management Science background. Each member was encouraged to contribute to the team effort according to his own area of expertise.

The integration of the modeling effort, with the organizational levels and branches it affected, was an extensive and demanding task. Inputs required were the distribution history and modes of shipment, geographical demand patterns, process characteristics, plant capacities, variable operating costs, transportation costs and constraints, and inventory configurations, costs, and constraints. These were fed into the model and processed by an optimization routine that produced plans for top management's analysis and review. On the basis of this review, revised projections and "what if" questions were formulated which were again presented to the model, thereby establishing a dynamic feedback process that provided still more refined and useful information. The overall design of the project team's strategic effort is shown in Figure 3. 
Figure 3. Project Design.

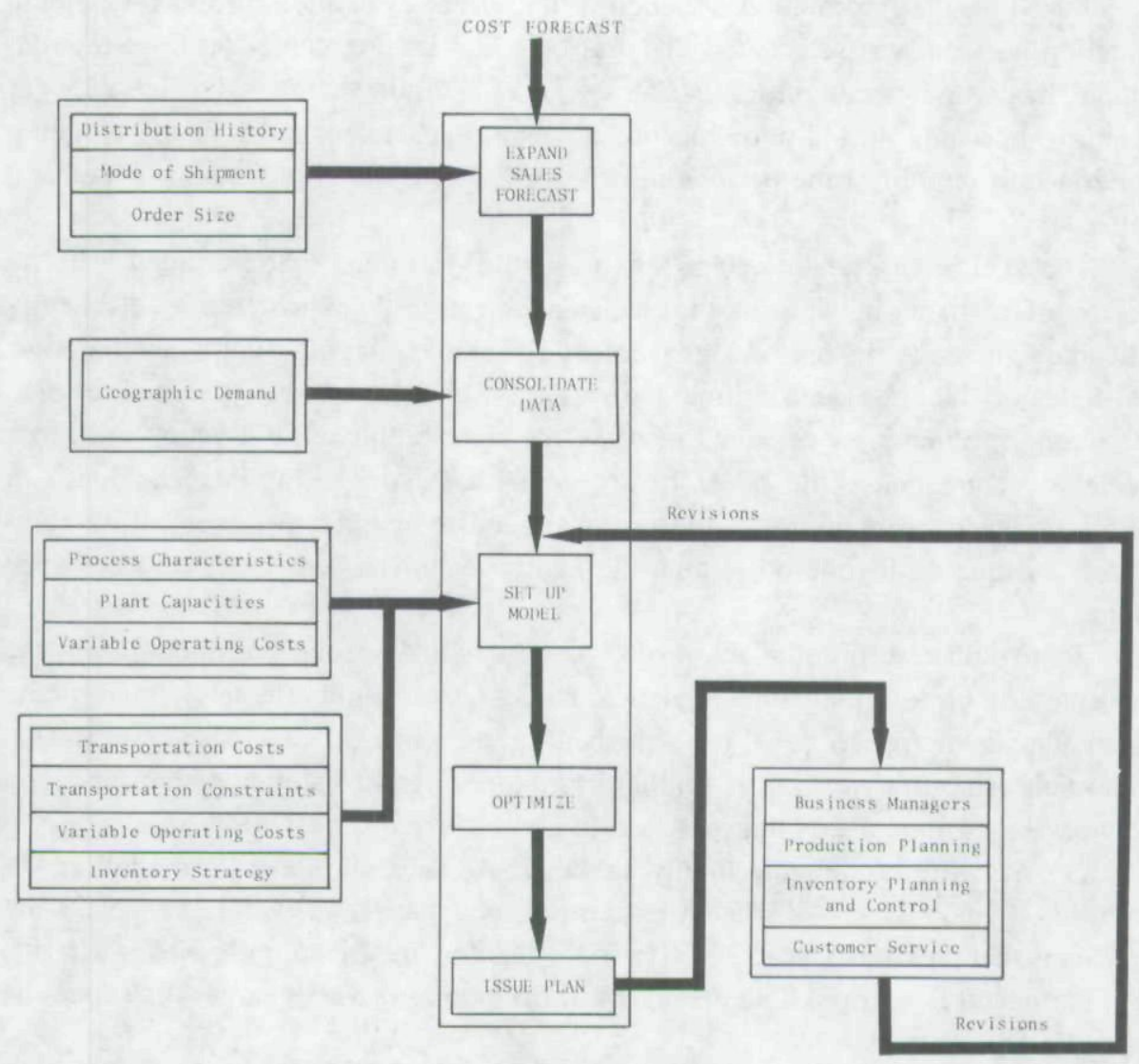

\section{Special network model considerations}

To make possible the dynamic feedback process of model review and revision, it was necessary to begin by charting Agrico's existing and proposed operations on a map of the United States. First, the existing and proposed supply sites were located on the map. They included Agrico's four production plants as well as points of potential product purchases and exchanges with coproducers. Next, existing and potential sites for bulk distribution centers were located on the map. They included the 78 distribution centers owned and operated by Agrico as well as the ones leased on an annual basis. Finally, all of the points of demand were located on the map. They included Agrico's 2000 clients as well as the points of potential product sales and exchanges with coproducers.

After constructing a map of Agrico's domestic operations, the project team transformed it into a more workable network model format. The two principal components of a network formulation are nodes and arcs. In this case, nodes (depicted by points, or circles) were used to represent the supply sites, distribution centers, and demand sites. The arcs (depicted by arrows) connect pairs of nodes, and indicate the possible ways to ship goods from supply sites to distribution centers and from these to demand sites. The orientation of an arc (direction of the arrow) indicates the allowable direction of shipment. 
In addition to the nodes and arcs, network models commonly have five data components: Supplies, Demands, Costs, Lower Bounds, and Upper Bounds. Supplies and demands are associated with nodes while costs, lower bounds, and upper bounds are associated with arcs. A simplified network diagram illustrating these data elements is presented in Figure 4. This diagram illustrates the feasible shipping routes between two supply sites ( $\mathrm{S} 1$ and $\mathrm{S} 2$ ), two distribution centers (D1 and D2), and three demand sites (C1, C2, and C3). The supplies and demands in Figure 4 appear in triangles attached to the associated nodes. For example, supply site 1 has a supply of 29 tons of product, and demand site 2 has a demand of 28 tons of product. In this illustration, none of the distribution centers has any supply or demand. The marginal shipping cost between a pair of nodes is given in the rectangle attached to the arc that connects the nodes. The lower and upper bounds indicate the allowable size of the shipment between a pair of nodes and are given in parentheses beside the corresponding arc. For instance, it costs $\$ 2$ per ton to ship from supply site 1 to distribution center 2 . The minimum shipment is 8 tons and the maximum is 20 tons.

Figure 4. Network Diagram of Agrico Facilities.

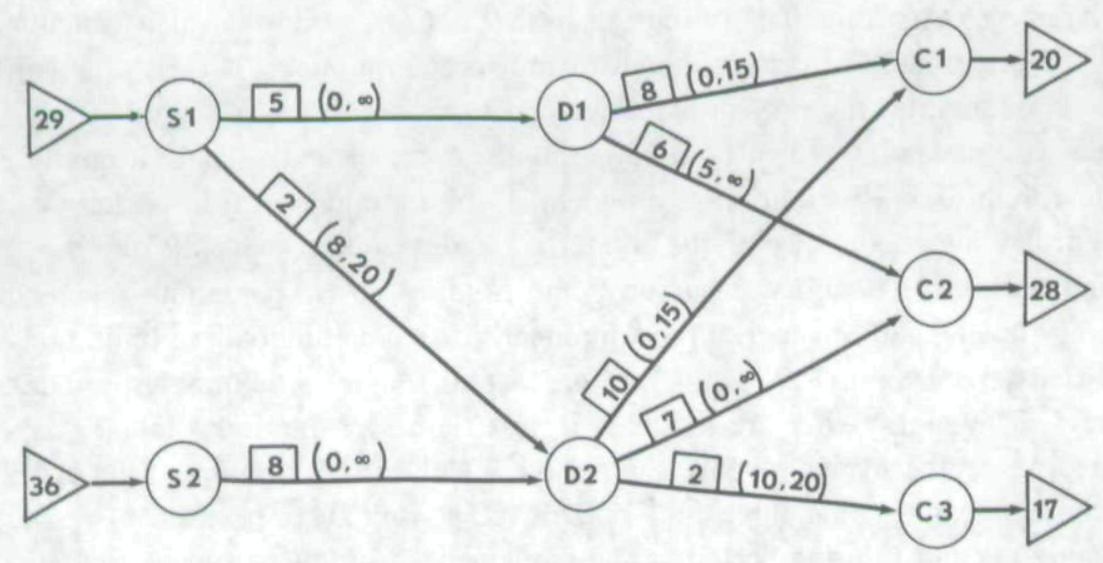

The lower bound on an arc in the network formulation allows the model to incorporate such features as contractual agreements to ship at least a certain amount of product between locations. The upper bound on an arc can be used to capture such things as management policies on shipment sizes or physical rate of movement limitations (e.g., pipeline limits).

\section{Elaborating the basic model form}

Once the fundamental network model form was understood by members of the project team, the next step was to elaborate it in order to handle the special considerations that applied to the real-world structure of Agrico's problem. For example, it was desired to give the model the ability to accommodate management's practice of 
setting lower and upper limits on supply quantities. This ability allows the model, instead of the manager, to select the exact levels of production, purchase, and exchange. The manager is required only to specify feasible ranges for these decisions. In the network formulation, this feature was implemented by adding a supply policy node and supply policy arcs to each of the supply sites.

This added construction provided an increased model capability that made it possible to handle the variable costs of production, purchase, and exchange. In an analogous fashion, the model was extended to enable fixed levels of demand at each demand site to be replaced by an estimated demand range. Demand policy arcs from each demand site to a demand policy node can be used to capture the variable revenue associated with selling the product or exchanging with a coproducer.

Additional problem considerations required somewhat more complex augmentations to the model. Analyses conducted with the aid of Agrico's production, distribution, and marketing staffs led to identifying the least cost alternatives for modes of transportation from the supply sites to the distribution centers. These were incorporated into the model by means of approporiate network constructions. Safeguards on the quality of customer service were provided by a preliminary culling of transportation links from distribution centers to demand sites and imposition of bounds on appropriate arcs.

Agrico's marketing staff raised the further consideration that many clients expressed a preference for certain modes of transportation during certain times of the year. Consequently, the project team decided to represent these clients by a set of demand site nodes instead of by a single node. A set of nodes made it possible to handle variances in distribution cost depending on the mode of transportation.

Further augmentations of the model were developed to handle the seasonal demand patterns, inventory capacities, and holding costs, beginning and ending inventory levels, and transportation equipment loading and unloading limitations. A simplified three-month "snapshot" of the overall model structure is provided in Figure 5. The supply sites are modeled in this figure by the nodes labeled Sit. For instance, $S_{21}$ represents supply site 2 in period 1 . The complex nature of the distribution centers requires that three nodes, $D_{j A t}, D_{j B t}$, and $D_{j c t}$, be used to represent distribution center $j$ during period $t$. The movement of product from supply site $i$ to distribution center $j$ during period $t$ is handled by the arc connecting Sit to $D_{j A t}$. The unloading (loading) dock at distribution center $j$ in period $t$ is modeled as the arc from $D_{j A t}$ to $D_{j B t}\left(D_{j B t}\right.$ to $D_{j C t}$ ). The long term storage of product during period $t$ at distribution center $j$ is captured by the arc connecting $D_{j B t}$ to $D_{j B t+1}$. The clients (by mode of transportation) are represented by the nodes labeled $C \mathrm{kmt}$. The shipment of product from the distribution centers to the clients is handled by the arcs from $D_{j c t}$ to $C \mathrm{kmt}$. For example, the rail shipments from distribution center 2 to customer 1 during period 3 are modeled by the arc from D2C3 to CIR3. The supply (demand) policy arcs are those that are connected to the node labeled SP (DP). 


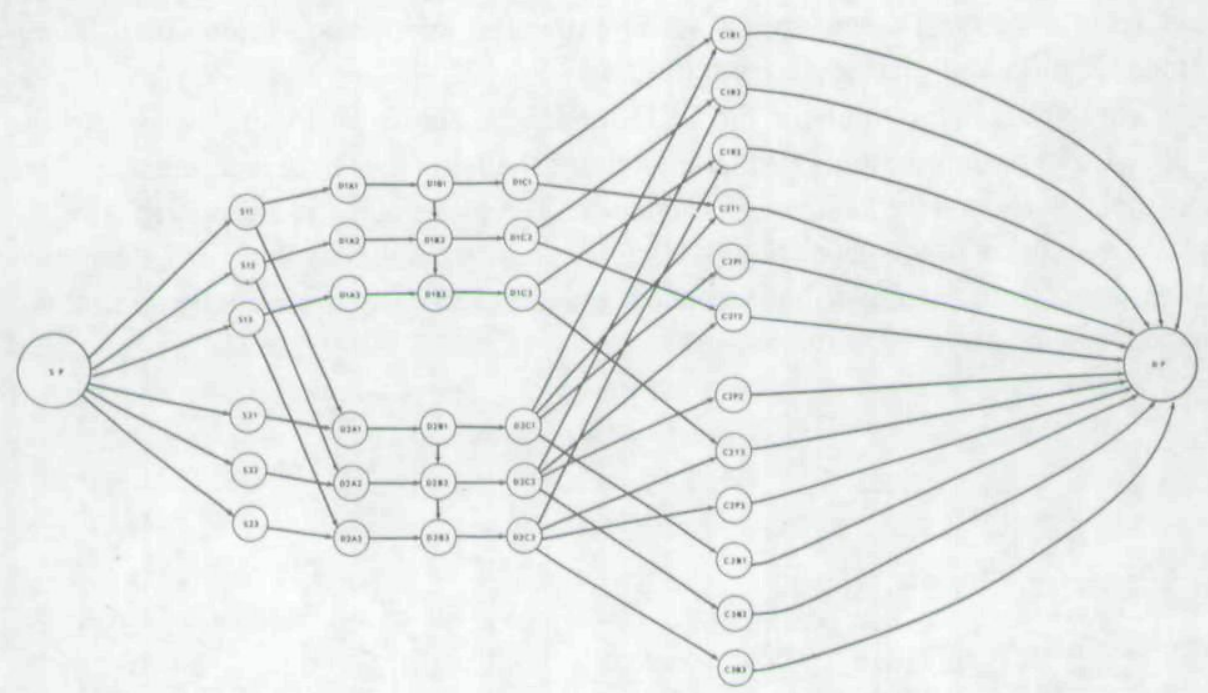

\section{LCD model}

One of the fundamental model components of Agrico's PDI system is the Least Cost Distribution (LCD) model. This basic model is used for many different types of analyses and policy evaluations and is sometimes augmented by additional variables and constraints. At other times, portions of the basic model are dropped from consideration. For instance, Agrico has used the model, so far, with no revenue values associated with the demand policy arcs. Thus, the LCD model has been used strictly to minimize costs.

For short-range planning, it is assumed that the plant and distribution center configuration is fixed. Consequently, for short-range analysis, the objective of the LCD model is to minimize the following "laid-in" costs:

- variable production costs,

- primary costs to move product to distribution center storage,

- secondary costs to move product to the client,

- variable costs associated with holding inventory,

- variable distribution center throughput costs.

The sum of these costs is minimized subject to the following constraints:

- demand volume of clients,

- supply availability at supply points,

- distribution center input-output capacity,

- inventory capacity,

- opening inventory levels,

- minimum closing inventory requirements,

- mode of shipment required.

For long-range planning, the LCD model is used to determine the optimal plant 
and distribution center configuration and size. For these types of analyses, the objectives are augmented to include minimization of plant expansion and fixed distribution center lease costs. The constraint set is expanded to include various distribution center location and plant expansion options.

The inputs and outputs of the LCD model are shown in Figure 6. Two of the especially important outputs of this model are the least cost distribution zone maps and the distribution center report summary. The zone maps are prepared directly from the solution to the network model. They show the counties that can be supplied at least cost from each distribution center and are used daily to manually control the placement of orders.

Figure 6. LCD System.

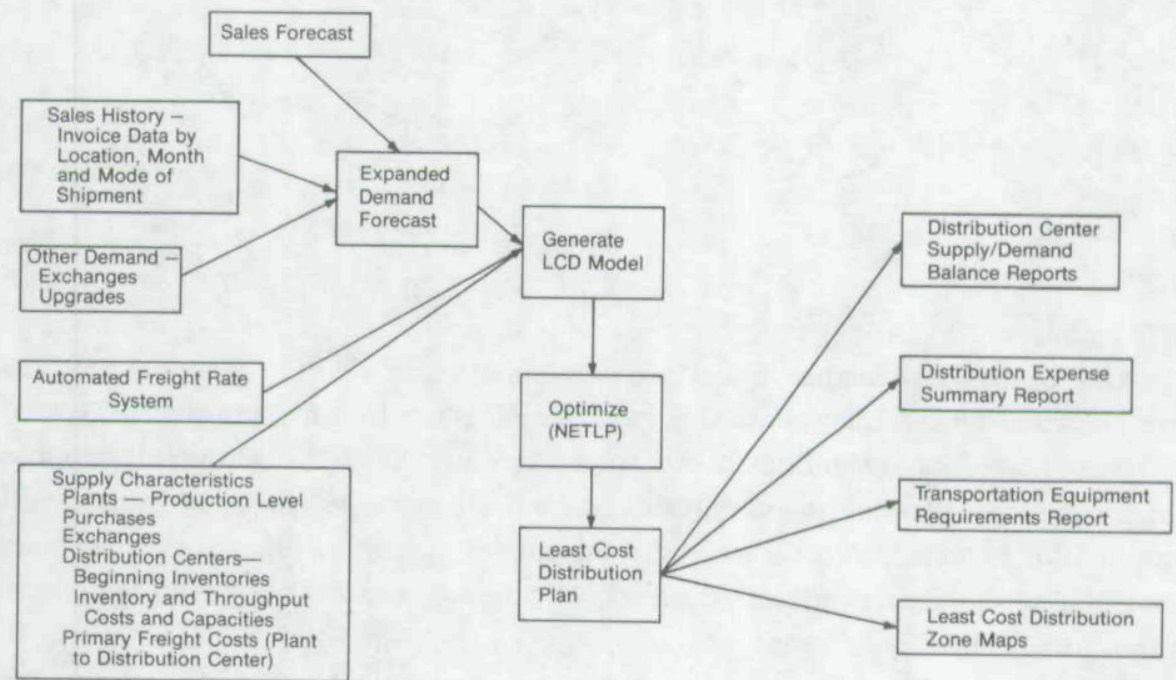

The distribution center report summary gives a full breakdown, by month and by transportation mode (truck, rail, barge, etc.) for each client. Clients are also grouped on the basis of type of sales, i.e., Agrico retailers, non-Agrico retailers, and national wholesale executive accounts.

The foregoing outputs, together with the others indicated in Figure 6, contribute markedly to the ease of implementing this model. The outputs also facilitate the companywide coordination essential to model review and updating. The success of the LCD model rests in no small part on the effectiveness of this coordination.

\section{Solving the LCD model - no small task}

The inclusion of multimodal shipping aspects and partitioning the planning horizon greatly increased the size and complexity of the LCD model. For this reason, the project team was careful to capture the production, inventory, and distribution constraints of the system in a network formulation for short-range planning. Even so, the typical size of the short-range LCD problem involves approximately 6000 equations and more than 35,000 variables. 
In fact, the apparently formidable task of solving this problem almost caused the study to be aborted before it began. To test the feasibility of solving the problem, Agrico obtained access to a primal simplex-based network code from its parent, The Williams Companies. Attempts to solve a problem with this code on a large-scale AMDAHL V-6 computer required approximately two and a half hours. This outcome was severely negative, due to the need for reasonable turnaround time to perform iterative solution analyses. As a result, the project was on the brink of being scrapped.

Fortunately, however, major recent innovations in network solution technology [5], [9], [10] came to the rescue. The project team recommended that Agrico undertake to solve the problem with an advanced and highly efficient code developed by Analysis, Research, and Computation (ARC), Inc. With management's approval, ARC's network code, ARCNET, was obtained and tested. ARCNET was able to reduce the solution time from two and a half hours to only 50 seconds! Because of the need to solve the short-range LCD model repeatedly, in order to answer "what if" questions concerning different demand structures and production/distribution scenarios, this occurrence was a vital element in the success of the project.

The project team's network expertise was also utilized to obtain highly efficient solution software for the long-range LCD model. This model is a large-scale, mixed integer, linear programming problem whose linear programming (LP) portion involves a large embedded network structure. Members of the project team had previously played a fundamental role in developing mathematical procedures [11], [16] for solving LP problems with embedded networks efficiently. However, at that time such procedures had never been implemented for use on a computer. Since management had faith in the project team, they authorized the team to negotiate a contract with ARC to develop such an LP system. This was the second and most crucial decision made by Agrico management for the solution of their models.

ARC developed a new LP solution system, called PNET/LP, which has proven to be far superior in performance to even the team's most optimistic expectations. The system, when compared against one of the fastest state-of-the-art LP systems, APEX-III, proved to be at least 75 times faster on medium size prototypes of Agrico's problems. PNET/LP normally solves Agrico's long-range LCD problems, involving 6250 equations and 23,000 variables, in less than 5 minutes, including all input and output. The value of this solution capability, in terms of providing management with a tool - the LCD model - which can be used on a, routine basis to evaluate planning alternatives, is difficult to overstate.

\section{Concluding remarks by Agrico management}

The following remarks regarding the success of this Management Science application at Agrico Chemical Company are given by David Wilson, Vice-President of Agrico Supply and Distribution:

The PDI planning system has had a widespread impact at Agrico. In addition to cost savings that exceed $\$ 8$ million in 1978 alone, the system has brought about improvements in nearly every phase of our production, distribution and inventory operations. 
We have recently used the PDI system, for example, to evaluate the benefit/cost impact of resizing an ammonia pipeline system and to determine the effects of pipeline tariff rate changes. Additionally, we have used the system to evaluate long-term conversion/exchange agreements affecting operations companywide. Also, the use of the model to assist in sizing our UAN solution distribution system has provided new insights on size and location of storage tanks.

A major nonquantifiable benefit has been a better and more thorough understanding of our Supply and Distribution operations. The PDI system has been particularly valuable to Agrico in the areas of marketing (by more clearly identifying the end-point demands of our customers and the transportation modes best suited to satisfy them) and supply and distribution (by more effectively relating distribution center operations to the most profitable shipping alternatives).

The ability to investigate the impact of various decision alternatives, before they are implemented, provides us with information to manage more intelligently. The "whys" of a particular solution are often more valuable than the "what" of an optimal solution, as optimal solutions are typically modified during implementation due to changes in real-world conditions. Insights into the "whys" of system behavior, gained through the investigation of alternative scenarios with the PDI system, have enabled us to respond more effectively to our operating environment.

The use of the LCD system has been so successful and encouraging that we are in the process of incorporating revenue data into the model and are considering extensions of the model to encompass our manufacturing and mining activities. These extensions of the model will enable marketing to evaluate the impact of new areas of demand and allow Agrico to gain the benefits of the PDI planning system in additional areas of management.

\section{REFERENCES}

[1] Barr, R. and Turner, J.S., "A New, Linear Programming Approach to Microdata File Merging," 1978 Compendium of Tax Research, Office of Tax Analysis, Department of the Treasury, Washington, D.C.

[2] Bartholdi, J., III, and Ratliff, H.D., "A Field Guide to Identifying Network Flow and Matching Problems," Research Report No. 77-12, Department of Industrial and Systems Engineering, University of Florida, Gainesville, Florida.

[3] Bazaraa, M. and Jarvis, J., Linear Programming and Network Flows, John Wiley \& Sons, New York, 1977.

[4] Bradley, G., "'Survey of Deterministic Networks," AIIE Transactions 7, 1975, pp. 222-234.

[5] Bradley, G., Brown, G., and Graves, G., "Design and Implementation of Large-Scale Primal Transshipment Algorithms," Management Science 24, 1977, pp. 1-35.

[6] Cunningham, W., "A Network Simplex Method," Mathematical Programming 11, 1976 pp. 105-116.

[7] Dennis, J., " "A High-Speed Computer Technique for the Transportation Problem," Journal of the Association for Computing Machinery 8, 1958, pp. 132-153.

[8] Glover, F., Hultz, J., and Klingman, D., "Improved Computer-Based Planning Techniques, Part I,"'Interfaces 8, 1978, pp. 16-25.

[9] Glover, F., Hultz, J., Klingman, D., and Stutz, J., "Generalized Networks: A Fundamental Computer-Based Planning Tool," Management Science 24, 1978, pp. 1209-1220.

[10] Glover, F., Karney, D., and Klingman, D., "Implementation and Computational Study on Start Procedures and Basis Change Criteria for a Primal Network Code," Networks 4, 1974, pp. 191212.

[11] Glover, F. and Klingman, D., "Models and Methods for Network-Related Problems," Proceedings of NATO Advanced Study Institute on Computer Methods in Practical Applications, Sogesta, Urbino, Italy, July 1977.

[12] Helgason, R. and Kennington, J., Algorithms for Network Programming, to be published.

[13] Jensen, P. and Bhaumik, G., "A Flow Augmentation Approach to the Network with Gains Minimum Cost Flow Problem,"'Management Science 23, 1977, pp. 631-643. 
[14] Johnson, E., "Flows in Networks," in Handbook of Operations Research, ed. by J. Moder and S. Elmaghraby, Van Nostrand Rineholt Co., 1978, pp. 183-205.

[15] Klingman, D. and Russell, R., "On Solving Constrained Transportation Problems," Operations Research 23, 1975, pp. 91-107.

[16] Maier, S., "A Compact Inverse Scheme Applied to a Multicommodity Network with Resource Constraints," Technical Report No. 71-8, Operations Research House, Stanford University, 1971.

[17] Mulvey, J., "Testing of a Large-Scale Network Optimization Program, " Mathematical Programming 15, 1978, pp. 291-315.

[18] Srinivasan, V, and Thompson, G., "Benefit-Cost Analysis of Coding Techniques for the Primal Transportation Algorithm," Journal of the Association for Computing Machinery 20, 1973, pp. $194-213$. 
Copyright 1979, by INFORMS, all rights reserved. Copyright of Interfaces is the property of INFORMS: Institute for Operations Research and its content may not be copied or emailed to multiple sites or posted to a listserv without the copyright holder's express written permission. However, users may print, download, or email articles for individual use. 